\title{
Meningioma of the optic nerve
}

\author{
SAMRUAY SHUANGSHOTI \\ From the Department of Pathology, Faculty of Medicine, Chulalongkorn University, Bangkok, \\ Thailand
}

The purpose of this communication is to report an instance of meningioma of the optic nerve found in Thailand, and to discuss the cellular origin and the mode of occurrence of the ectopic meningiomas.

\section{Case report}

A 49-year-old Thai woman had observed a painless swelling of the right eye 2 years before, and one year later suffered blurring of vision in this eye. At the time of admission to hospital, the eye was blind and painful.

\section{Examination}

There was proptosis of the right eye with limitation of ocular movements in all directions. The fully dilated pupil did not react to light, and there was closed-angle glaucoma. Roentgenograms of the skull disclosed enlargement of the right optic foramen. The left eye was normal.

The clinical impression was that of a retrobulbar tumour.

\section{Operation}

The right orbit was explored on the second day in hospital and the right eyeball was enucleated with a retrobulbar tumour which was irregularly-shaped, encapsulated, grey, and rubbery. The tumour encased the optic nerve (Fig. I, overleaf) and invaded the medial wall of the orbital fossa. A small portion of the tumour within the enlarged optic foramen was left behind.

Microscopically (Fig. 2, overleaf), the neoplasm consisted of numerous plump syncytial meningocytes which frequently formed whorls. Their ovoid and vesicular nuclei were often vacuolated.

\section{Course}

8 months later, the patient experienced paraesthesia of the forehead on the right side. A brain scan and carotid angiogram showed evidence of a mass lesion in the sellar region. A frontal craniotomy was performed. A circumscribed tumour occupying mainly the right half of the anterior cranial fossa was partially attached to the stump of the right optic nerve. The rostral portion of the mass was within the optic canal. This mass was totally eradicated with the attached part of the neutral stump. Histologically, it was the same as that described above.

Result

The patient was well when she was seen a year after the craniotomy.

\section{Comment}

The diagnosis was meningocytic meningioma encasing the right optic nerve with intraorbital and intracranial involvement. 


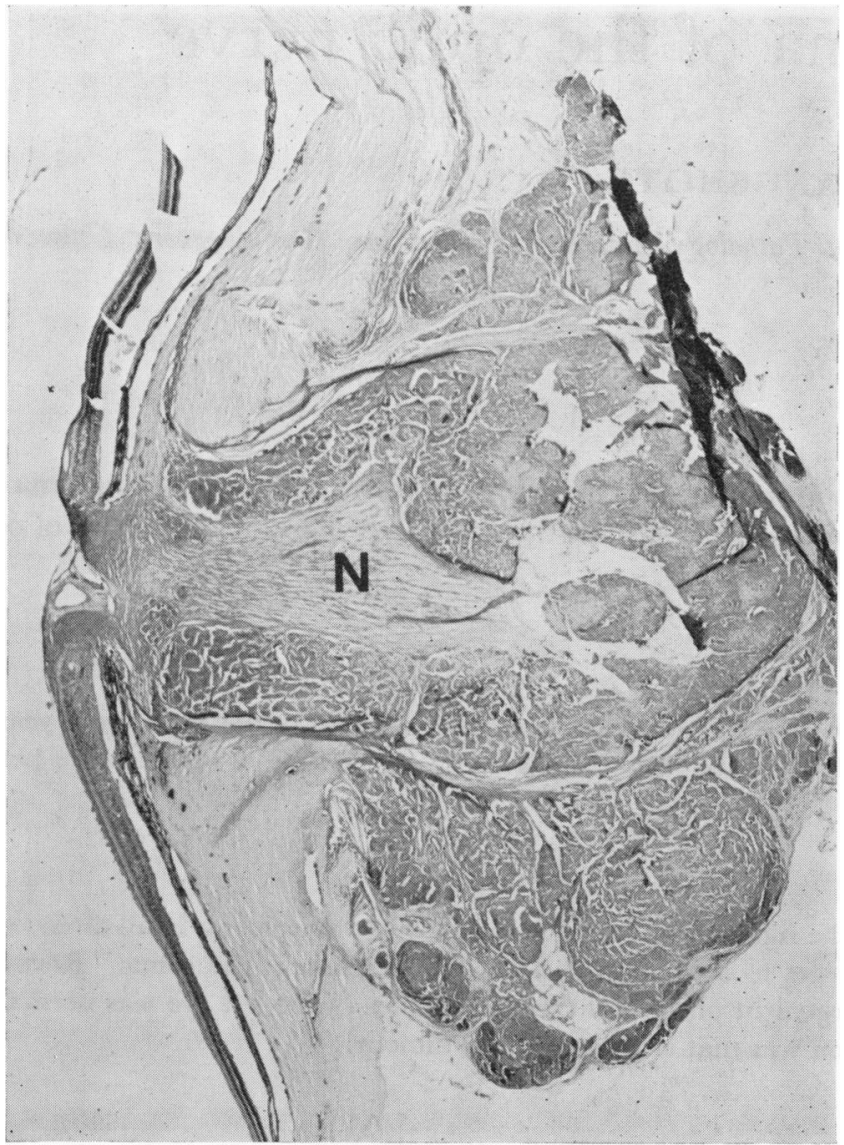

FIG. I Meningioma encasing and invading the optic nerve $(\mathcal{N})$. Haematoxylin and eosin. $\times 10$

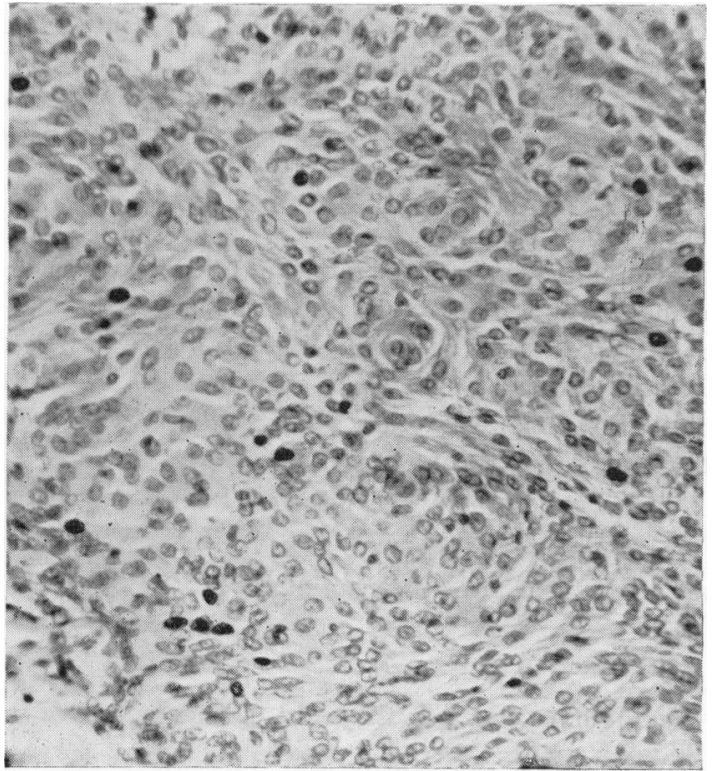

FIG. 2 Numerous meningocytes arranged in clusters and whorls. Note syncytial appearance of tumour cells. Haematoxylin and eosin. $\times 100$ 


\section{Discussion}

The presence of meningocytes with whorl formation establishes the diagnosis of meningioma (Lapresle, Netsky, and Zimmerman, 1952). These tumours may be situated entirely within the orbital fossa, or may arise in the confines of the optic canal with subsequent extension into the orbit or the cranium, or both. They usually surround or are adherent to the optic nerve (Craig and Gogela, I949), but are sometimes not related to the nerve (Benedict, I923; Wiegmann, I929).

Meningocytes (meningothelial or arachnoidal cells) are widely scattered within the arachnoid throughout the central nervous system, but are most numerous where the arachnoidal villi (Pacchionian granulations) are present. They usually cluster at the tips of the arachnoidal villi, and are called "cap cells". Courville and Abbott (1942) showed the transition between the meningocyctic cluster of an arachnoidal villus and a small symptomless prefrontal meningioma encountered accidentally in a necropsy of an old woman.

The visual apparatus is developed from multiple sources of tissue; the surface ectoderm, the neural ectoderm, and the mesenchyme (Jordan and Kindred, r948). In the early human embryo, paired neuroepithelium-lined outpouchings develop in the anterior aspect of the prosencephalon, becoming the optic vesicles. The latter are surrounded by mesenchyme. The vesicle later elongates, and the proximal part constricts to form the optic stalk. The dilated distal portion is related closely to the surface ectoderm which soon becomes thickened to form the lens placode. In the later somite embryo, the optic cup is connected to the prosencephalon by the constricted tubular optic stalk. The neuroepithelial wall of the optic cup gives rise to the retina, the epithelia of the ciliary body, and the iris. Further differentation of the retina yields numerous nerve fibres which extend into the optic stalk, leading to an increase in the thickness of the walls of the latter. Consequently, the lumen of the optic stalk is obliterated and becomes the optic nerve. Soon after formation of the optic cup and lens, the mesenchyme surrounding the optic cup becomes condensed and differentiates into the choroid, sclera, stroma of the iris, ciliary body, and cornea. This developmental process takes place at the same time as the mesenchyme surrounding the optic nerve, brain, and spinal cord differentiates into the sheath of the optic nerve, the dura mater, and the leptomeninges. The sheath of the optic nerve and the leptomeninges, therefore, are analogous structures, and the space between the sheath and the nerve itself is in continuity with the cerebral subarachnoid space.

Meningiomas, therefore, may arise from the sheath of the optic nerve. Craig and Gogela (1949) demonstrated clusters of the meningocytic cellular rests in the optic sheath. It has been suggested that these cellular rests are also present in the sheaths of other cranial and spinal nerves at their points of exit from the skull and the vertebral column (Hoye, Hoar, and Murray, I96o). It is most likely that the meningioma in the present patient arose from the optic sheath, because it encased the optic nerve.

The theory of the meningocytic cellular rests, however, fails to explain the occurrence of a few orbital meningiomas lying outside the cone of the ocular muscles without connection to the optic sheath (Benedict, I923; Wiegmann, I929). The ectopic meningioma recorded by Bain and Shnitka (1956) was entirely embedded within the scalp without bony attachment, and was unrelated to the foramina of the skull. In the case described by Harkin and Reed (1969), the tumour was located in the brachial plexus, at a relatively great distance from the skull and the vertebral column. Moreover, meningocytes are not the only type of cells found in meningiomas; some meningiomas contain fibroblasts or mixed meningocytes and fibroblasts (Lapresle and others, 1952), or mesenchymal cells (Bailey 
and Bucy, r93I) with various mesenchymal components such as bone, cartilage, and adipose tissue (Lapresle and others, 1952). Bain and Shnitka (1956) suggested that subcutaneous meningiomas without bony attachment arose from Schwann cells. They called attention to the similarity between cells comprising meningocytic meningiomas, and naevus cells regarded by Masson (I95I) as of Schwannian origin. Bain and Shnitka (1956) believed that Schwann cells may produce meningocytes, because they have a common "neuroectodermal" origin according to some workers (Harvey, Burr, and Van Campenhout, I933; Kernohan and Sayre, I952). Indeed, cases have been reported of meningiomas containing melanin (Turnbull and Tom. 1963) as is often seen in dermal naevi.

Shuangshoti and Netsky (1966a), in their study of the histogenesis of the human choroid plexus, however, suggested a mesenchymal origin for meningocytes. Mesenchymal cells are the main type found in the interstitium of the choroid plexus when the primordium of the plexus first appears. With progression of the differentiation of the plexus, haematopoietic elements, fibroblasts, fibres of connective tissue, blood vessels, and meningocytes appear, and the mesenchymal cells gradually decrease in number to disappear at full development. These findings suggest that meningocytes are mesenchymal in origin as are the fibroblasts and the stroma of the choroid plexus which consists of leptomeninges. Shuangshoti and Netsky ( $1966 \mathrm{~b}$ ) regarded meningocytes as modified fibroblasts. Schwann's cells produce reticulin fibres (Murray and Stout, 1942; Nathaniel and Pease, 1963; Thomas, 1964), a feature not observed in neurones and neuroglial cells which are universally accepted as neuroepithelial derivatives. Ablation of the neural crest did not prevent formation of Schwann's cells in the distal segment of the nerve, and these cells were absent in the proximal portion near the root (Yntema, 1943). These findings again suggest that Schwann cells do not develop from the "neuroectoderm" as some investigators (Harrison, I924; Raven, I937) believe, but favour a mesenchymal origin. We believe that meningiomas may arise directly from mesenchymal cells as well as from meningocytes, fibroblasts, Schwann cells, or a combination of such cells. It is appropriate to categorize meningioma as a mesenchymal neoplasm. This mesenchymal concept explains the occurrence of meningiomas at various unusual locations such as the paranasal air sinuses (Hill, I962), external surface of the calvarium (Alpers and Harrow, 1932), a nasal cavity (Lindstrom and Lindstrom, 1969), and subcutis (Bain and Shnitka, I956; Hoye and others, I960; Harkin and Reed, r969). This idea also explains the diverse histological features of meningiomas as they are linked with the usual behaviour of mesenchymal tumours (Stout, 1948). Mesenchymal cells and their derivatives are multipotential; in appropriate circumstances, they may differentiate into fibrous, osseous, chondrous, adipose, vascular, and meningeal tissues (Willis, 1960). Most of these tissues may present in mengiomas.

\section{Summary}

A case is reported of a meningioma encasing the optic nerve. The sheath of this nerve and the leptomeninges are developmentally analogous structures, being mesenchymal in origin. Meningiomas may, therefore, arise from the optic nerve sheath, but a few intraorbital meningiomas have been recorded which were unrelated to the optic nerve. The concept of the cellular origin of meningiomas is reviewed, and the conclusion is drawn that meningocytes, fibroblasts, and Schwann cells are mesenchymal in type.

This work was supported by a Chulalongkorn University Research Grant on the Occasion of the Royal Silver Jubilee Anniversary(1971). Prof. Somsak Dhechakaisaya, head of the Department of Pathology, Chulalongkorn! University, gave permission to study this case. 


\section{References}

ALPERs, B. and harrow, R. (1932) Arch. Neurol. Psychiat., 28, 339

BaIley, P. and BUCY, P. C. (1931) Amer. F. Cancer, 15, I5

BaIn, C. O., and shnitka, T. K. (1956) Arch. Derm. (Chicago), 74, 590

BENEDICT, W. L. (1923) Amer. F. Ophthal., 6, I83

COURVille, c. B., and ABвotT, K. A. (1942) J. Neuropath. exp. Neurol., r, 337

GRAig, W. M., and gogela, L. J. (1949) Amer. J. Ophthal., 32, I663

HARKIN, J. C., and REED, R. J. (1969) "Tumors of the Peripheral Nervous System. Atlas of Tumor

Pathology", 2nd ser., fasc. 3, p. I8. Armed Forces Institute of Pathology, Washington, D.C. harrison, R. (1924) F. comp. Neurol., 37, 123

harvey, s. G., BurR, H. S., and Van Campenhout, e. (1933) Arch. Neurol. Psychiat., 29, 683

HILL, G. L. (1962) Arch. Otolaryng., 76, 547

hOYE, s. J., hOAR, c. s., and MURRAY, J. E. (1960) Amer. F. Surg., 100, 486

JORDAN, H. E. and KINDRED, J. E. (1948) "Textbook of Embryology", 5th ed., pp. 415-427. Appleton-Century, New York

KERNohan, J. W., and SAYRE, G. P. (1952) "Tumors of the Central Nervous System, Atlas of Tumor

Pathology", section X, fasc. 35 and 37, p. 97. Armed Forces Institute of Pathology, Washington, D.G.

Lapresle, J., netsky, m. G., and zimmerman, H. M. (1952) Amer. F. Path., 28, 757

LINDSTRÖM, C. G., and LINDSTRÖM, D. W. (1969) Acta otolaryng., 68, 45 I

MASSON, P. (195I) Cancer, 4 , 9

MURRay, M. R., and Stout, A. P. (1942) Amer. F. Path., 18, 585

NATHANIEL, E. J. H., and PEASE, D. C. (1963) F. Ultrastruct. Res., 9, 5 I I

RAVEN, C. P. (1937) F. comp. Neurol., 67, 22 I

ShUANGSHOti, s., and NeTsky, м. G. (1966a) Amer. F. Anat., 118, 283

-
stout, A. P. (1948) Ann. Surg., 127, 278

THOMAS, P. K. (1964) J. Cell Biol., 23, 375

TURNBULl, I. м., and том, м. I. (1963) $\mathcal{7}$. Neurosurg., 20, 76

wiegmann, E. (1929) Klin. Mbl. Augenheilk., 82, 232

willis, R. A. (1960) "Pathology of Tumours", 3rd ed., pp. 722-731. Butterworths, London

yNTEMA, c. k. (1943) F. exp. Zool., 94, 319 